\title{
Reflections on the Self and Other: Understanding the Journey
}

\author{
Todd Jobbitt* \\ Graduate School of Education, Hankuk University of Foreign Studies, 270 Imun-dong, Dongdaemun-gu, Seoul, \\ 130-791, Korea \\ *Corresponding Author: Todd Jobbitt, Graduate School of Education, Hankuk University of Foreign \\ Studies, 270 Imun-dong, Dongdaemun-gu, Seoul, 130-791, Korea
}

\begin{abstract}
Knowing where one's own personal and professional spheres meet a learning community can be a significant self-discovery process. This author attempts to show, through various self-reflections of himself and in interactions with other people, places and events, how developing an understanding of both these areas can lead to a greater sense of awareness via reflective practice and hence purpose in future cultural knowing and understanding, as well as contributing to a stronger improvement in the author's personal and professional relationships and subsequent classroom practices. The author ends with some final thoughts and practical suggestions for enhancing one's reflective practices.
\end{abstract}

Keywords: Self-Reflection, Reflection, Reflective Practice, Self and Other, Cultural Knowing

\section{INTRODUCTION}

Reflective practice, described by Schon (in Ferraro, 2000) “involves thoughtfully considering one's own experiences in applying knowledge to practice while being coached by professionals in the discipline" (p. 2). My own loose analogy could be described as a teacher walking down a different path, a path that many avoid, akin to Emerson's "Do not go where the path may lead, go instead where there is no path and leave a trail" (Ralph Waldo Emerson). Just as I concur with the opinion expressed in Emerson's quote, I also agree that the opposite can be true: one's experience shapes how one sees one's own identity. Of course, interaction with others plays a huge part in shaping that experience and its future impact on one's self. Measurement of that personal learning and identity formation can take some time though. In past teacher-learner experiences with peers and students in Korea, where I began my teaching career, it took several years for me to finally recognize limitations in my teacher-learner growth. Good reflective practice helped in this process, albeit mine a more retrospective process as argued against by Akbari (2007). Nonetheless, a conclusion that a breakaway point had been reached in my teaching was when I began to feel that my personal and professional identities could move beyond that context and that more education in an environment that did encourage reflective practice, was needed.

Attending graduate school at The School for International Training (now SIT Graduate Institute) made me realize that I was at a critical stage in my teacher and personal identity formation. Central to understanding these developing identities were the processes of group work with new peers, and narrative reflection about my past learning. These narratives were supported by two particular ideas with the first being David Kolb's Experiential Learning Cycle (Table 1), as adapted by Moran (2001). The diamond symbol within Kolb's cycle symbolizes Moran's (2001) view of the five dimensions of culture - products, practices, persons, perspectives and communities - and the interplay between these dimensions. This symbiosis is important as it relates to language and culture learnings in Korea in my early teaching career, actual non-reflective learning that can be very important, as pointed out by Korthagen (2001). A earlier illustration of this challenge was raised by Schon (1987, in Van Manen, 1995) in that "professional education undervalues practical knowledge and grants privileged status to intellectual scientific and rational knowledge that may only be marginally relevant to practical teaching" (p. 33). Thus, though appreciative of the frameworks, I proceeded with hopeful caution.

Kolb's cycle had been gone through continuously in my learning processes, both in and outside the classroom, the latter being the more active side of language exploration. With no time for language training due to a heavy teaching schedule, reliance on interactive functions within Korean society became the main learning approach. 


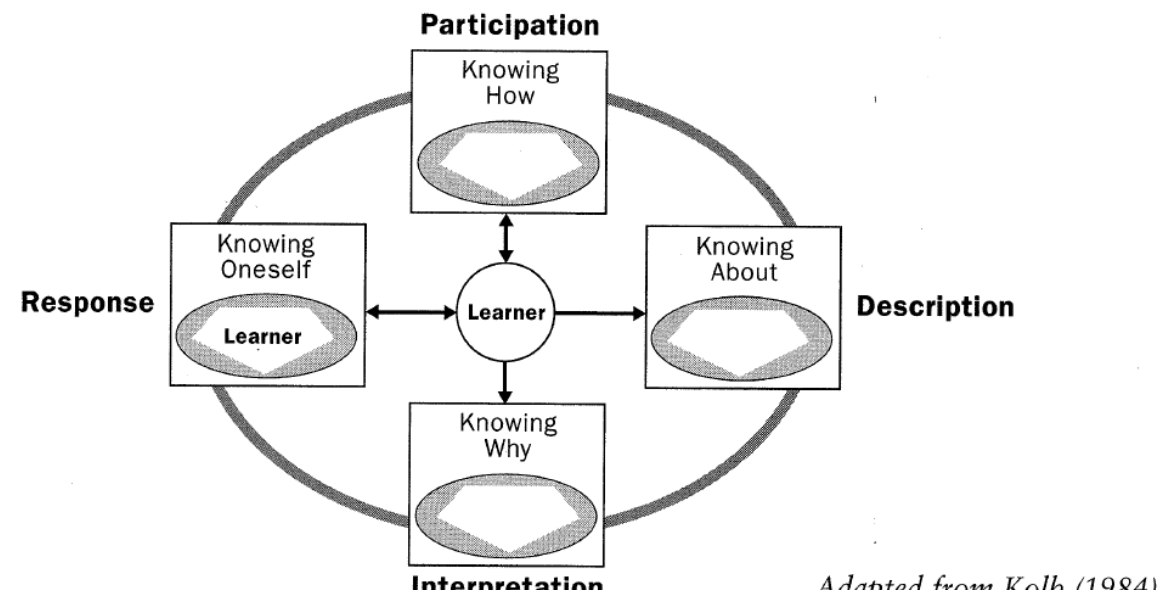

Table1. David Kolb's Experiential Learning Cycle (Moran, 2001)

(Kolb's cycle encourages continual self-evaluation in one's teaching processes.)

A second framework that helped me understand more about these experiences was the Cultural Knowing framework (Table 2) (Moran, 2001). A vast amount of learning about both Korean society and language was transformative in my ability to co-exist with others. Over time, being able to share those experiences proved beneficial. See Martin and Nakayama (1999; 2010) for a more comprehensive overview of paradigms relating to culture and communication in contexts.

Table2. Pat Moran's Cultural Knowings: Content, Activities, Outcomes

\begin{tabular}{l|l|l|c|}
\multicolumn{1}{c}{ Content } & \multicolumn{1}{c}{ Activities } & Outcomes \\
\cline { 2 - 4 } $\begin{array}{l}\text { Knowing } \\
\text { About } \\
\text { Knowing } \\
\text { How }\end{array}$ & cultural information & gathering information & cultural knowledge \\
\cline { 2 - 4 } $\begin{array}{l}\text { Knowing } \\
\text { Why } \\
\text { Knowing } \\
\text { Oneself }\end{array}$ & cultural practices & developing skills & cultural behaviors \\
\cline { 2 - 4 } & cultural perspectives & discovering explanations & cultural understanding \\
\cline { 2 - 4 } & self & reflection & self-awareness \\
\cline { 2 - 4 } & & &
\end{tabular}

(Moran's Cultural Knowings table delineates 'knowing' into manageable chunks.)

Though initially an awkward practice, I soon came to appreciate the results of sharing these experiences with other pre or in-service teacher-trainees who were at similar points in understanding their own self-growth. The process of narrative reflection also was a major influence in learning about this teacher-learner identity because it increased awareness of my whole being, not just my teacherbeing. Interaction through various communities, such as my own family, SIT peers, and in how living and traveling in foreign cultures had shaped different sides of my identity, was illuminating; much had changed within me by going through these processes. I came to feel a much stronger sense of personal growth and confidence in my teaching abilities after demystifying some of these connections.

\section{MATERIALS AND METHODS}

Understanding this teaching identity was important because of deficiencies I had felt in my teaching abilities. Applying motivational realism - my own self reacting to the environment and continuing on to my teaching context - overseas was partially, as later realized in retrospect, a way to instill motivation in myself to finish my contract commitments to the school, and my own personal sense of obligation of finishing what was started. I suppose that, for me, this was as powerfully transformative in a way not unlike how it may be for others, as described by English and Irving (2012). But understanding "what started" shifted from being simply a means to a paycheck to a personally and professionally transformative process.

I came to recognize that within the classroom culture that I had developed differences in personal and professional perspectives on how I was teaching versus how I truly wanted to teach students and 
engage with them in the classroom. I find this split similar to Bennet's (1993) perspective of how, when in a given cultural context, one continually connects to and splits away from the very context in which on is teaching; for me, the school in which I taught. I did not want to remain stuck in the same place, at the same school, teaching the same text as I had seen others do. I believe that a distinct lack of encouragement of formal training in my teaching context and the unmentored independence required by private school teaching contributed to this distancing. Although there was a great amount of teaching practice there was virtually no theory to supplement it which ultimately made my teaching shortcomings come to the fore, against a backdrop of truly understanding why these changes and challenges were occurring. In explaining principles for beginning teachers, Korthagen et al (2006) puts this more succinctly as, "a need to respond to a range of conflicting and competing demands" ( $p$. 1025), something I had fell all too much in this earlier teaching context.

This last realization was a firmer application of why my motivational realism grew during my overseas tenure: I really did want to be a better teacher, and a better, more well-rounded person capable of handling the finer aspects of teaching.Feeling burnt out, yet trying to do my best was tiresome, and the realization came that I had to do what was best for me, and not continue trying in vain. I needed an option to expand on my self-perceived greater ability. Small improvements to my teaching methodology were not doing anything substantial for me, nor for my students. Perceptive 'gaps' in my knowledge, skills, attitudes and awareness of teaching knowledge ultimately caused my teaching foundation to crumble, but for the better.

It became more evident to me as I was writing this paper that motivational realism was and still is my own personal 'super-charged' intrinsic motivation - the desire to be a better teacher for all aspects related to my teaching contexts. Recognizing, evaluating, and enhancing intrinsic motivation toward all of these areas is the central tenet of motivational realism. Though I am still validating and applying reflective practice to my learning contexts many years after graduate school, I still feel a positive challenge to meet these goals directly.

An area of expression in my pre-graduate teaching days and graduate school attendance was evidenced through various teaching sub-competencies:

- awareness of my own opinions and feelings as a participant in group experiences

- awareness in the forms of feelings, opinions, interaction styles and the way they affect others

- attitudes of openness to, and valuing of differences in other people

- knowledge of the multiple dimensions of identity

- skills of articulating one's own understanding of shared events as distinct from that of others experiences, and eliciting others' experiences of these events

The competencies were chosen due to various interactions dealing with several miscommunications, cultural misunderstandings, increasing cognizance of aspects of diversity among peers, processes that I had gone through in both my overseas living and at graduate school, and lastly, an opportunity to explore my perspectives on team-teaching and peer group-learning.

\section{RESULTS AND DISCUSSION}

The first sub-competency of 'awareness of my own opinions and feelings as a participant in group experiences' took place in the first fall term of my graduate school attendance, where I was asked to participate in a group 'venting' process, after a classmate/community meeting.After the meeting, I wrote:

Several peers could not understand another's comments during the meeting, and were visibly upset. While not recalling specific words, the context of this small meeting was to try to understand why what was said had been said in the first place, and what it meant. I helped facilitate my fellow peers, and my own, understanding of this person's intentions, partly due to my own personal understanding of that single peer. The process of exploring our feelings was positive, and it a good bonding process.

While I was able to express more feeling in an impromptu meeting with my peers, doing so in a classroom process had been more difficult. An additional journal entry illustrated my growing pains in failing to clearly recognize or even express my feelings in a group process by noting: 
I need to work on opening up a bit more with my feelings related to experiences of language learning to my group. I guess that I'm still sorting out some of this, so it is not exactly clear to me either, but I am working on it.

We (classmates) recognized the need to address our feelings but understanding how to 'validate' our feelings in relationship to teaching was still a bit of an unknown that needed to be explored further. I realized that withholding feelings about experiences, and attempting to discern how others were thinking instead of asking them directly, could limit the group learning process. This made me work harder at expressing my feelings in later group activities.

I realized that I was not the only one having difficulty with group processes after being introduced to a new teaching method in an Approaches to Teaching class. In this class, I examined peer differences in feelings and opinions while participating in a seminar. The particular aspects of joy and easiness created on the part of the teacher during a Suggestopedia session were of key interest to me, as I had tried similar techniques when teaching children overseas. I noted that 'instructor liveliness' seemed to make my peers feel uncomfortable; there was seeming visible resistance in participating in segments of the Suggestopedia process. I came to the conclusion that:

It takes a decision on the part of the student whether or not they want to incorporate this joy into their learning, much like I did. Judging from prior feedback sessions it seemed that most of them did not allow the 'suggestion' of joyfulness to creep in. That element of 'joyful suggestiveness' that my peers refused to accept, to me, meant that they were not willing to alter or change their perceptions in relationship to what was being taught.

The seminar was enjoyable because it paralleled my past teaching experiences. The motivators (joy and easiness) were not meant to detract, but enhance the material, but what was most relevant to me was how 'joy and easiness' were interpreted by the learners: the definitions may vary, as in this Suggestopedia demonstration. For this reason, it had become important to me to be open to extended definitions of conditions that I want to create for my students in the classroom, and of my intentions for doing so.

Whereas sharing my feelings with group partners was initially selective, and broadened over time, the opposite was true of my interpersonal communication. I was generally very friendly but had also presumed at times that others "knew what I meant" automatically, meaning that "my awareness of my own feelings, opinions and interaction styles and how they affected others' still needed work.

An Intercultural Communication course(ICC) paper that I had written, 'A Developing Cultural Framework' was a mixed blessing of both low and high awareness about how my language choice and interaction style affected others adversely, and what I learned from these episodes. I noticed that in a few

Relationships with persons on this campus I have had difficulty... in conveying my intentions clearly when speaking; I was not as aware as I should have been in these situations, and that is a process that I have been working on. For example, I sometimes use sarcasm to make a point, but it is not understood by most foreign students. I don't like to be misunderstood, especially when I mean no harm, but the fact of the matter is that I should perhaps not use the language in the first place if it is going to cause confusion.

This last sentence was important because my concern with a concluding statement to make a point blinded me to how and what others were formulating about me as a result of my language choice. I therefore learned that the perception of what I was saying, my meaning, was totally different from what they were 'hearing' me say. By discussing this problem with a peer, I gained significant awareness of how consequential these language choices had been on classmates. Modifying this behavior after the discussion and clarifying my choice of language with an affected peer helped me feel a sense of success in regard this issue. This was a good example of how self-reflection may not always be present, but it still does need to be nurtured.

Being raised in a middle-class community did not present opportunities to experience and appreciate true intercultural diversity, or nurture 'attitudes of openness to and valuing of differences in people'. That changed upon working with international students in my undergraduate school, through organizing 'study abroad' opportunities for American students. This exposure through friendship and 
volunteer work was an initial step to my increasing awareness of European and Asian perspectives on US culture - their perspectives made me re-evaluate American culture, to a small degree initially. As time went by, my curiosity deepened about other cultures, and English teaching became the key to unlocking that curiosity.

As I still live overseas, many of my experiences in my early teaching career broadened an appreciation of cultural differences, positive or negative: it continues to this day. But defining them subjectively before attending graduate school was boosted by having a second perspective, even long after a particular experience. I gained better clarity about 'my attitudes of openness to and valuing of differences in people' from an ICC paper 'The Culture of Todd' written by a classmate. Her interpretations reinforced my personal viewpoints, as her key observation about cultural differences I experienced early on in my teaching career in Korea, stating:

...he feels that he became more tolerant to public behavior that differed from what he was used to, such as occasional pushing and shoving... that he had to become even more patient in his interactions in Korea. This suggests that he was sensing significant cultural differences between what he had considered "normal" behavior... and that he felt the need to adapt to those situations in some way."

Raising my awareness of Korean socio-cultural practices allowed me to more easily clarify for myself why certain actions, though strikingly different to my culture, were deemed normal or 'natural' in Korea, thereby helping me understand these differences better.

Attending the graduate program at SIT had been one of the most intense intercultural experiences of my life due to the variety of international students and the intensive program format. Having such close contact with peers had opened many doors of cultural understanding throughout the year, by my curiosity peaked when the topic of diversity became a central issue on campus.

A diversity training seminar helped me to decide to explore how much of an influence my perceptions about values could influence my own behavior. Resultantly, after attending, I reflected in my journal on how the need to maintain my awareness of differences in others is vital for my continued interpersonal growth. The workshop helped me feel more confident in pursuing dialogue with persons of all colors and creeds. I wrote at the time that the workshop I participated in "helped me realize that obtaining the 'big picture' is important before jumping to conclusions" and that "I need to be more evaluative in my evaluations (of others) " during initial meetings.

Ironically, by studying at my graduate school, which is in my native country, I felt that I was better able to 'ground' or stance myself within my own culture. This contributed to making me feel more comfortable when trying to understand the range of diversity issues that were occurring on campus (sexual orientation, race, gender, etc.), this an interesting retreat from Bennet's 'integration' stage to 'defense.' It seemed, in retrospect and rightfully so, that the 'culture of SIT' itself was making me work harder at understanding my cultural being even more than some overseas experiences. This learning has been paralleled in post-graduate life in increasing my understanding of the dimensions of culture, race and language identity formation, as well as how these factors influence motivational realism to date.

A final sub-competency that was fulfilled during my graduate school tenure was that of having the 'skills of articulating one's own understanding of shared events as distinct from that of others experiences, and eliciting others' experiences of these events'. This was manifested in an internship experience overseas which had encouraged me to try new teaching techniques. Part of the reason for this was that team teaching was an assigned duty. This sounded like a helpful idea, believing that the experience would lead me to a greater potential for significant growth when working with others.

This team teaching experience was simply easy. As my partner and I were both from similar American backgrounds of class and race, there were no intercultural differences in our preparationand approach to the teaching of class content. This allowed us the flexibility to additionally focus on each other's style, and of course, student involvement in the lessons. A comment I made in my journal was, "Today was an excellent experience, that of team teaching; I feel that I learned a lot. It was not entirely smooth; different working with another person in a shared teaching space. Big difference between knowing about and knowing how to do it." 
As I had lacked training in 'proper' team-teaching methodology, I felt that the opportunity to work with, observe, and provide feedback to each other was mutually beneficial to our professional development. Perhaps this is due to a perspective, lightly ascribed and shared by Johnson \& Golombek (2002) stating that, "professional development emerges froma process of reshaping teachers' existing knowledge, beliefs, and practices rather than simply imposing new theories, methods, or materials on teachers."

The shared learning from the team teaching differed much from earlier active learning with groupteaching of Silent Way techniques helped me appreciate and contrast these experiences. I taught Hangul to two peers, which brought mixed results for them initially, and somewhat for me too. A reflective essay written about this experience revealed our shared responses; we concurred that we had been thoroughly and overly repetitive in the teaching of the pronunciation, for example. In this process, I saw how my feelings (of happiness) about learning differed from my peers, helping me to realize that evaluating a language process soon after it occurred could help identify the variables responsible for feelings that resulted.

This teaching experience was significant because it helped me recognize that 'learning to be aware' of the learning process while simultaneously doing it was not so difficult. Yet my self-awareness at that time still had significant gaps, which took longer to process. Realizing that I needed to continue maintaining the sense of self that I had brought into new learning environments, and project that toward new persons in that context, was illuminating. Through these process, I had chosen a better approach of how to do this - through learning experientially, by doing reflective narratives and peer sharing - practices that continue to this day.

\section{CONCLUSION}

Knowing more about how to examine and to be critical of one's beliefs, attitudes, and practices is in line with the idea of reflective practice and critical inquiry, both vital for progression as a learning teacher. Not only knowing about oneself, but others too, specifically recognizing the need to be more open when dialoging with mentors, peers and students in a teaching context, can be just as helpful. Creating the conditions for today's students requires much effort and the desire for a learning community has distinct challenges, as presciently noted by Larrivee (2000), that, "changing demands call for teaching styles that better align with emerging metaphors of teacher as social mediator, learning facilitator, and reflective practitioner", roles still much needed in present-day teaching contexts (p. 293). There are many ways to enlightenment vie reflective practice, and Larraviee (2000),further, offers several practical guiding principles toward the process of a teacher becoming a reflective practitioner:

- Make time for solitary reflection (daily practice via journaling)

- Become a perpetual problem-solver (meet natural resistance positively)

- Question the Status Quo (question institutionalized definitions, not beliefs)

- Accept tasks that contribute to the organization (decreases personal damage)

Although my graduate school days have long since passed, I continue to stumble, fall, and yet grow as a teacher, all the while examining my beliefs, assumptions and expectations in new teaching contexts. As I continue teaching, hope remains that others' objective clarity will assist me in these personal evaluations and practices, as I show allowance and understanding for others' perspectives of their learning experiences. Keeping these principles in mind, new paths await.

\section{REFERENCES}

[1] Ferraro, J. M. (2000). Reflective Practice and Professional Development. ERIC Digest. Retrieved from: https://files.eric.ed.gov/fulltext/ED449120.pdf

[2] Akbari, R. (2007). Reflections on reflection: A critical appraisal of reflective practices in L2 teacher education. System, 35(2), 192-207.

[3] Moran, Patrick (2001) Teaching Culture: Perspectives in Practice. Heinle \& Heinle.

[4] Korthagen, F. (2001). Linking Practice and Theory: The Pedagogy of Realistic Teacher Interpretation. Conference proceeding, Annual Meeting of the American Educational Research Association, Seattle, Pp. 1-6. Retrieved from: https://pdfs.semanticscholar.org/be40/15bb54daa4d71a56236e5b0f0e8b4f02e9d9.pdf 
[5] Van Manen, M. (1995). On the epistemology of reflective practice. Teachers and Teaching 1(1), pp. 3350 .

[6] Martin, Judith \& Nakayama, Thomas (2010) Intercultural Communication in Contexts.

[7] Martin, J. N., \& Nakayama, T. K. (1999). Thinking dialectically about culture and communication. Communication theory, 9(1), 1-25.

[8] English, L. M. \& Irving, C. J. (2012). Transformative learning with women: A critical review proposing linkages for the personal and political spheres. Jossey-Bass.

[9] Bennet, Milton (1993) Towards Ethnorelativism: A Developmental Model of Intercultural

[10] Korthagen, F., Loughran, J., \& Russell, T. (2006). Developing fundamental principles for teacher education programs and practices. Teaching and teacher education, 22(8), 1020-1041.

[11] Johnson, K. E. \& Golombek, P. R. (2002). Teachers' Narrative Inquiry as Professional Development. Cambridge University Press.

[12] Larrivee, B. (2000). Transforming teaching practice: Becoming the critically reflective teacher. Reflective practice, 1(3), 293-307.

\section{AUTHOR's BIOGRAPHY}

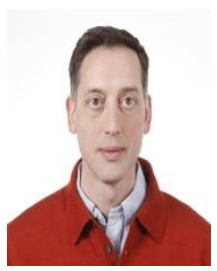

Todd Jobbitt is an Assistant Professor in the Graduate School of Education at Hankuk University of Foreign Studies, Seoul, Korea. His research interests include L2 composition, peer review and extensive reading.

Citation: Todd Jobbitt. "Reflections on the Self and Other: Understanding the Journey" International Journal on Studies in English Language and Literature (IJSELL), vol 6, no. 4, 2018, pp. 31-37. doi:http://dx.doi.org/10.20431/2347-3134.0604004.

Copyright: (C) 2018 Authors. This is an open-access article distributed under the terms of the Creative Commons Attribution License, which permits unrestricted use, distribution, and reproduction in any medium, provided the original author and source are credited. 